\title{
DYSLEXIC CHILDREN'S READING APPLICATION: DESIGN FOR AFFECTION
}

\section{Husniza Husni ${ }^{1}$, Zulikha Jamaludinn ${ }^{2}$ and Fakhrul Anuar Aziz ${ }^{3}$}

\author{
${ }^{182}$ School of Computing \\ ${ }^{3}$ School of Multimedia Technology and Communication \\ UUM College of Arts and Sciences \\ Universiti Utara Malaysia \\ 06010 Sintok, Kedah, Malaysia
}

Corresponding author: husniza@uum.edu.my ${ }^{1}$

\begin{abstract}
This article presents an interaction design model which considers the affective dimension for a reading application for dyslexic children. The research on the design model for the reading tutor was motivated by the need to offer dyslexic children with an effective and fun learning process. It acknowledges the challenge in designing an acceptable interaction design (IxD) model considering the differences in reading style, preference, and habits of dyslexics. The model was developed based on existing theoretical models combined with the findings from observations and unstructured interviews conducted involving 28, 7 to 14 year old, dyslexic children. A goal-directed design is adopted as the methodology to design such a model. The model's effectiveness and usefulness is now being tested in a special class for dyslexic children. It is hoped that the outcome could be used to further develop guidelines and standards in designing applications for users with specific impairments.
\end{abstract}

Keywords: Interaction design, automatic reading tutor, affective engineering, dyslexic children.

\section{INTRODUCTION}

Reading involves a set of skills a child needs to develop over time. The skills include phonemic awareness, phonics, fluency, vocabulary, and text comprehension. The development of these skills is acquired almost 
automatically for most people. Unfortunately for dyslexics, such skills require them to put in more effort to master. Besides, they need extra or different strategies/methods to grasp the skills and learn to read. Due to their difficulties in reading, dyslexia is perceived to be a deficit in the acquisition of sufficient skills for the aforementioned task due to the phonological deficit theory (Lundberg, 1995; Shaywitz, 1996; Snowling, 2000; Wolf, 1999). Thus, concerted efforts have been put in to help them read from conventional teaching methods to computer-based application as it is more interesting with animations, multi-coloured texts and sounds (Lundberg 1995; Lundberg \& Olofsson, 1993; Olofsson, 1992; Olson \& Wise, 1992). Since reading is such a challenge, having an automated reading tutor (ART) is therefore essential as a tool to create the interest towards reading. in other words, affection towards reading needs to be created or stimulated so that the children are able to enjoy the process of learning to read as much as possible to help them develop their reading skills naturally.

It is argued that the current state-of-the-art applications that are available to support reading for children, especially those who have special difficulties such as dyslexia, are not designed specifically to facilitate learning to read. Although they are designed to support reading, the interfaces however, do not take into consideration the attributes of dyslexic children, such as the choice of foreground and background colours that could help ease reading for dyslexics.

Irlen (2005) has listed eight background colours (see Figure 1), all in a pastel-coloured mode, which can facilitate dyslexics to read better. Affective aspects of a reading tutor is the key that influence the positive emotion of these children (Te'eni, Carey, \& Zhang, 2007). Hence, based on what Te'eni, Carey, and Zhang had stated, it is viewed that the application should adopt an interaction design model that fits in specifically to these special needs of learners. Therefore, the objective of this work is to propose an affective IxD model specifically for dyslexic children reading. The model should take into account the affective attributes of the children, prior to translating them into ART. By applying the attributes of the children into the ART, it is hoped that a specifically-designed art could be developed, which is able to recognize their readings and cope with phonetically similar errors (Husniza \& Zulikha, 2009), and that which could offer some affection that is appealing to the learners. 


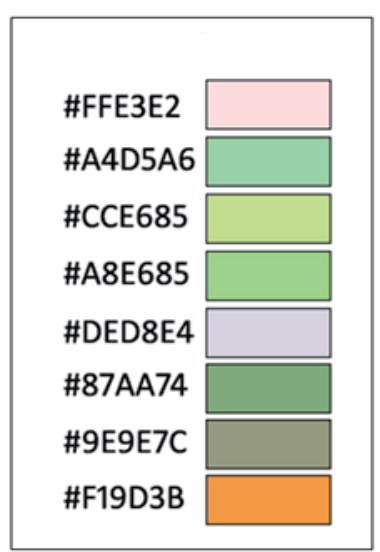

Figure 1. Eight colour codes proposed by Irlen (2005).

To discuss this further, the next section is dedicated to reviewing the literatures related to affection and reading in relation to ART in order to build the theoretical background of this work. The following section further relates to the discussion on the need for a careful and specific design of interaction between users and ART. Next, the methodology is presented followed by the deliverables, which is the IxD model with suitable design criteria.

\section{THEORETICAL BACKGROUND}

Theoretically, affect is referred to as a valence subjective experience involving positive or negative perception or pleasing or displeasing feelings (Desmet, 2007). The valence subjective experience, or in this case the degree of attractiveness of the ART, serves as a basis of the core affect theory (Russell, 2003) as depicted in Figure 2. The hedonic dimension (horizontal line) represents pleasure and displeasure whereas the activation dimension (vertical line) represents the activated or deactivated mode. In order to differentiate the user's affection state towards a product, these two dimensions could be combined to show either positive affect or negative affect depending upon the specific quarter in the core of the circle where the user's state resides. Therefore an ART that could create affection towards reading should be designed so that the learners mode resides in the positive hedonic dimension and at the same time is activated to engage in the learning process. 


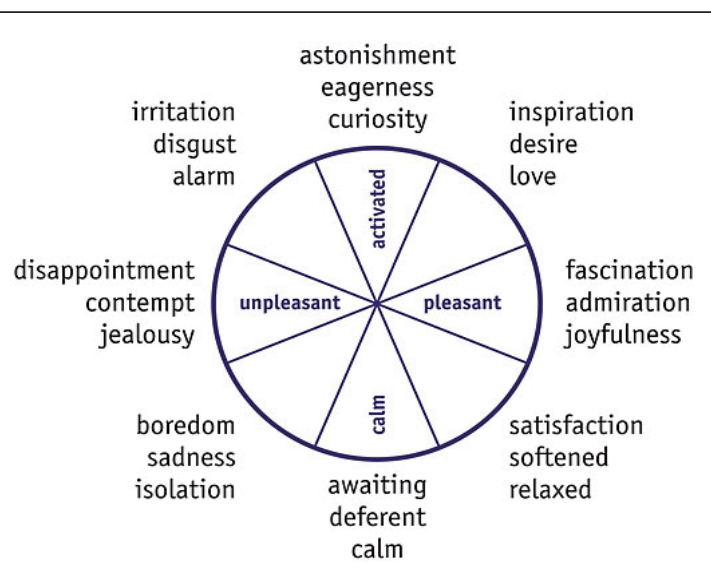

Figure 2. Core affect theory adapted from Russell (2003) and Desmet (2007).

To design such an ART, theories underlying dyslexia could provide a guide towards determining or identifying certain characteristics or features an ART should have. Table 1 summarizes the theories and provides a brief description of each of the theories related to the cause of dyslexia (Fawcett, Nicolson, 1992; Panlesu et al., 2001; Shayuitz \& Shayurita, 1999; Stein, 1997; Stein \& Walsh, 1997). Besides, it also highlights the effects to dyslexic children and suggests help that can be rendered to overcome their difficulties.

Table 1

Summary of Related Theories with Dyslexia and Their Effects

\begin{tabular}{|c|c|c|c|c|}
\hline Theory & Main cause & Description & $\begin{array}{l}\text { Effects to } \\
\text { Dyslexic Children } \\
\text { (DC) }\end{array}$ & Help \\
\hline $\begin{array}{l}\text { Phonological } \\
\text { deficit }\end{array}$ & $\begin{array}{l}\text { - Genetic/brain } \\
\text { difference. } \\
\text { - Perisylvian } \\
\text { part of left } \\
\text { hemisphere. } \\
\text { - Cerebral } \\
\text { deficits. }\end{array}$ & $\begin{array}{l}\text { - Phonological } \\
\text { coding can } \\
\text { be referred to } \\
\text { as systematic } \\
\text { relationship } \\
\text { between an } \\
\text { alphabet and its } \\
\text { sound. }\end{array}$ & $\begin{array}{l}\text { - Difficulties } \\
\text { in identifying } \\
\text { sequence and } \\
\text { sounding out } \\
\text { words. } \\
\text { - } \text { Problems with } \\
\text { rhyme, mix of } \\
\text { sounds, no-word } \\
\text { repetitions. } \\
\text { - Confused with } \\
\text { similar sounds } \\
\text { (e.g.paku, } \\
\text { pasu). }\end{array}$ & $\begin{array}{l}\text { - DC need } \\
\text { pronunciation } \\
\text { exercise. } \\
\text { - Reading } \\
\text { materials and } \\
\text { content with } \\
\text { structure are } \\
\text { interactive } \\
\text { in nature for } \\
\text { reading exercise } \\
\text { - Make them } \\
\text { listen to sounds } \\
\text { that match with } \\
\text { spelling. }\end{array}$ \\
\hline
\end{tabular}

(continued) 


\begin{tabular}{|c|c|c|c|c|}
\hline Theory & Main cause & Description & $\begin{array}{c}\text { Effects to } \\
\text { Dyslexic Children } \\
\text { (DC) }\end{array}$ & Help \\
\hline $\begin{array}{l}\text { Low working } \\
\text { memory }\end{array}$ & $\begin{array}{l}\text { Deficits in } \\
\text { short term } \\
\text { memory in the } \\
\text { front lobus of } \\
\text { the brain, right } \\
\text { hemisphere } \\
\text { (video), and } \\
\text { left hemisphere } \\
\text { (audio). }\end{array}$ & $\begin{array}{l}\text { Memory } \\
\text { processing } \\
\text { involving } 4 \text { main } \\
\text { components: } \\
\text { 1) audio memory } \\
\text { (including } \\
\text { phonology); } \\
\text { 2) visual memory } \\
\text { (including } \\
\text { orthography } \\
\text { or the shape of } \\
\text { words); } \\
\text { 3) procedural } \\
\text { or movement } \\
\text { memory (a.k.a. } \\
\text { habit memory, } \\
\text { e.g. riding a } \\
\text { bicycle); } \\
\text { 4) semantic } \\
\text { memory }\end{array}$ & $\begin{array}{l}\text { - Inefficient use } \\
\text { of working } \\
\text { memory. } \\
\text { - problems in } \\
\text { translating } \\
\text { visual } \\
\text { information to } \\
\text { phonological } \\
\text { representation, } \\
\text { thus limiting } \\
\text { the ability to } \\
\text { learn new words } \\
\text { when reading. }\end{array}$ & $\begin{array}{l}\text { DC should be } \\
\text { given a chance } \\
\text { to try out new } \\
\text { learning without } \\
\text { too much } \\
\text { urgency. }\end{array}$ \\
\hline $\begin{array}{l}\text { Visual } \\
\text { deficits }\end{array}$ & $\begin{array}{l}\text { Deficits } \\
\text { in visual } \\
\text { magnocellular } \\
\text { system (a } \\
\text { group of } \\
\text { neurons as path } \\
\text { for transferring } \\
\text { electrical } \\
\text { signals from } \\
\text { eyes to the } \\
\text { brain). }\end{array}$ & $\begin{array}{l}\text { Dyslexics fail or } \\
\text { have difficulties } \\
\text { to process } \\
\text { information sent } \\
\text { from the eyes. }\end{array}$ & $\begin{array}{l}\text { - unstable and } \\
\text { vibrating } \\
\text { binocular } \\
\text { vision. } \\
\text { - confusing the } \\
\text { sequence of } \\
\text { letters and } \\
\text { causing weak } \\
\text { memory for } \\
\text { visual } \\
\text { information. }\end{array}$ & $\begin{array}{l}\text { - } \text { eye muscle } \\
\text { exercise. } \\
\text { - } \text { provide choices } \\
\text { of background } \\
\text { colour as } \\
\text { recommended } \\
\text { by experts. } \\
\text { - provide audio } \\
\text { support. } \\
\text { - make an } \\
\text { obvious visual } \\
\text { differences for } \\
\text { similar looking } \\
\text { texts. }\end{array}$ \\
\hline $\begin{array}{l}\text { Temporal } \\
\text { or timing } \\
\text { difficulties }\end{array}$ & $\begin{array}{l}\text { - magnocellular } \\
\text { differences } \\
\text { (audio or } \\
\text { visual). } \\
\text { - only effects } \\
\text { temporary } \\
\text { processing. }\end{array}$ & $\begin{array}{l}\text { Deficits in the } \\
\text { part of the brain } \\
\text { that controls } \\
\text { sounds and } \\
\text { rapid visual } \\
\text { information. }\end{array}$ & $\begin{array}{l}\text { - DC have } \\
\text { difficulties } \\
\text { in processing } \\
\text { rapid sounds } \\
\text { and visual } \\
\text { information. } \\
\text { - DC need } \\
\text { more time to } \\
\text { learn, process } \\
\text { information, } \\
\text { and give } \\
\text { response. }\end{array}$ & 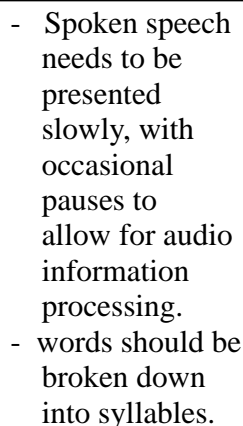 \\
\hline
\end{tabular}

Source: Paulesu et al. (1996); Frith (1997); Brunswick et al. (1999); Griffiths \& Frith (2002); Baddeley (1986); Gathercole \& Baddeley (1993); Evans (2001); Stein \& Walsh (1997); Wolf \& Garzia (1993); Miller \& Tallal (1995); Stein \&Walsh (1997); Fawcett \& Nicolson (1992). 
Based on Table 1, it can be concluded that most of the underlying theories or hypotheses of dyslexia are caused by three factors: 1) visual deficits; 2) auditory deficits; or 3) both visual and auditory deficits. As briefly explained in the table, the main cause in each theory has effects on the ability to read for dyslexic children. Hence, suggestions to help overcome their difficulties would be to minimize the visual cues/information by providing them with auditory support and presenting them with an interface design that would reduce their visual load. It is hoped that by taking into consideration all the effects and suggestions, the design of an ART could be more appealing and interesting thus initiating their learning mode to reside in the activated-pleasant-calm mode as depicted in Figure 2.

The positive state is important as dyslexics are often stressed in schools due to dealing with activities related to reading and writing. Thus, although learners should reach the activated mode, it is essential to ensure that the design also caters for calmness in order to avoid them from feeling stressful which may later disrupt the learning process. Hence, to ensure users reach the positive affect state, the ART needs to be specifically designed by incorporating the children's affective characteristics towards reading as suggested by Fakhrul, Husniza, and Zulikha (2010). For that, affective engineering is used to elicit requirements that can create pleasure and activation to achieve the above two positive dimensions as shown in the core affect theory illustrated in Figure 1. However, this does not mean that calmness should not be taken into consideration. The affective attributes incorporated into the ART are meant to also deliver ease of reading such as using suitable combination of background and foreground colours and suitable font types and sizes thus avoiding stress.

Different reading styles and unique reading approaches of these specific children have long been a challenge for designers to come up with an acceptable interaction design (Zulikha, Husniza \& Fakhrul, 2011). Emotional characteristics towards reading such as likes, dislikes, motivation, and satisfaction, which are very much related to affection, are essential in designing the suitable reading application to help them learn to read and develop their interest in reading. In relation to the core affect theory, a design based on emotional characteristics would very much help to stimulate the learners to achieve the positive affect mode - pleasant and activated (but also incorporate the calmness in the design to maximize the learning process).

Through our initial observation, the learners' positive affect can be directly spotted when they are interacting with computer-based applications (such as ART). However, it can only be easy with a proper design of interaction in the application's user interface. Designing such interactions have always been far 
from perfect especially for dyslexic children due to the variability in their reading patterns (Zulikha, et al., 2011). Figure 3 shows a model of reading which classifies poor word reading as classic dyslexia. According to Wright (2010), this model holds that reading is a function of one's ability to read the words $(r w)$ on the page $(p 1 \ldots n)$ and the ability to apply linguistic (al) and reasoning skills (ar) to the decoded text, i.e. moving towards broader language skills in the model:

$$
\text { Reading }=r w_{p 1 \ldots p n}+\operatorname{skill}(a l+r s)
$$

Thus, dyslexia affects the children's ability to read at word level, which later affects their ability to comprehend what they have read.

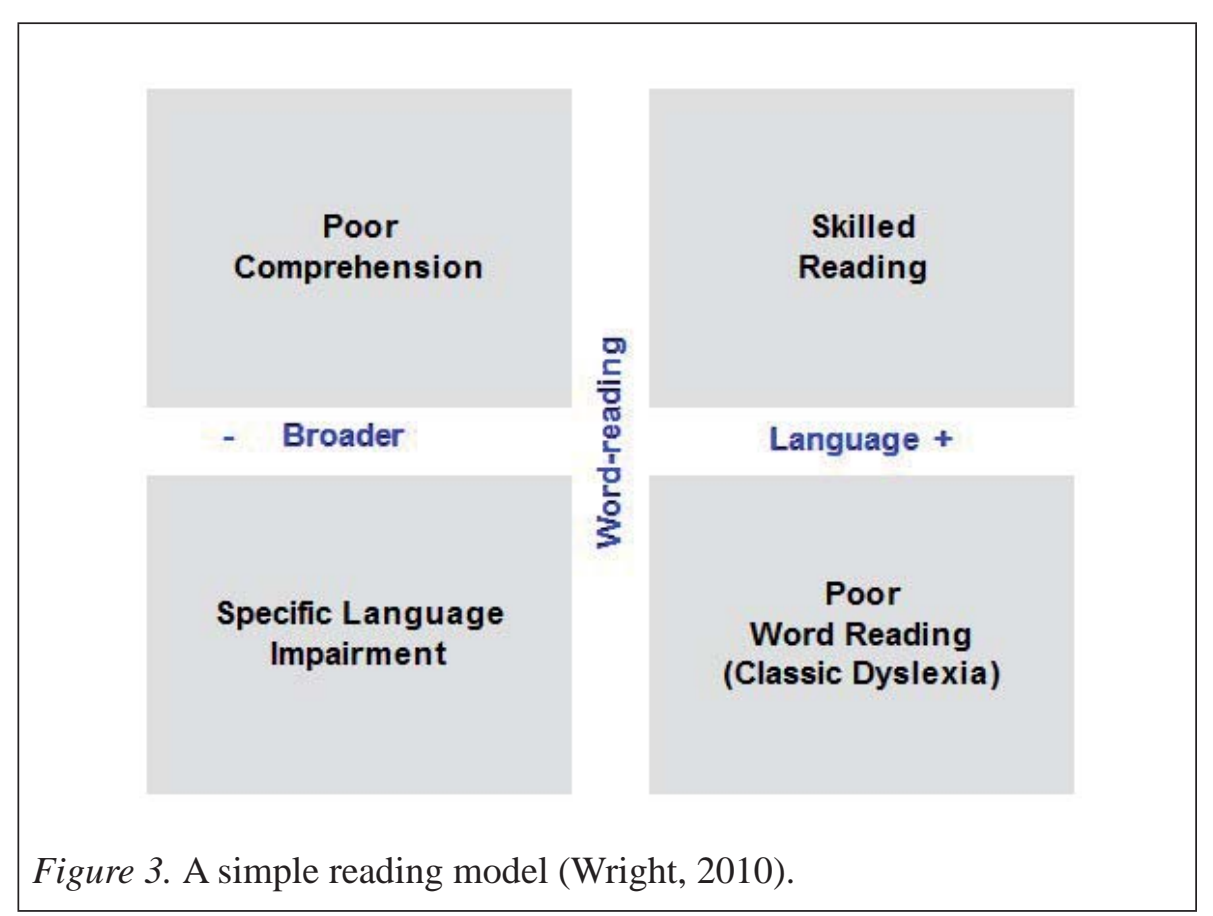

At word level, is there a way to incorporate affective values into an ART? If so, how can we design and develop an ART with such affection incorporated into it? We believe that the incorporation of instructional strategies into existing interaction models should result in a more appropriate framework for an effective ART. Thus, to include the affective values into the ART, we aimed at combining two well-known interaction models, namely Norman's Interaction Model (1986) and Abowd and Beal's (1991) model. The models, supported by the core affect theory will then be translated into interaction design (IxD) strategies in designing the user interface for an ART meant for the children. 


\section{The interaction models}

Norman's interaction model consists of a logical execution-evaluation cycle, mainly a method of conceptualizing the philosophy of computer interfaces. Figure 4 depicts the original Norman's model of interaction which breaks down the process of interaction between human and a computer-based application into seven phases. Beginning with forming the goal, an intention will be formed, followed by specifying and executing action (moves to physical activity). After that, a user will perceive the state of the world, interpret it and evaluate the outcome. Execution-evaluation loop will occur because users will take further action based on their evaluation.

Abowd and Beale (1991) expanded Norman's model by giving a more realistic description of interaction. They include the system with its four major components namely User, Input, System, and Output. The interface sits between the user and the computer system as shown in Figure 5. Thus, the interface plays an important role to facilitate effective interaction for the users. Since the users here are the special need learners with dyslexia, the interface design becomes more and more crucial towards creating a sense of affection for the reading task.

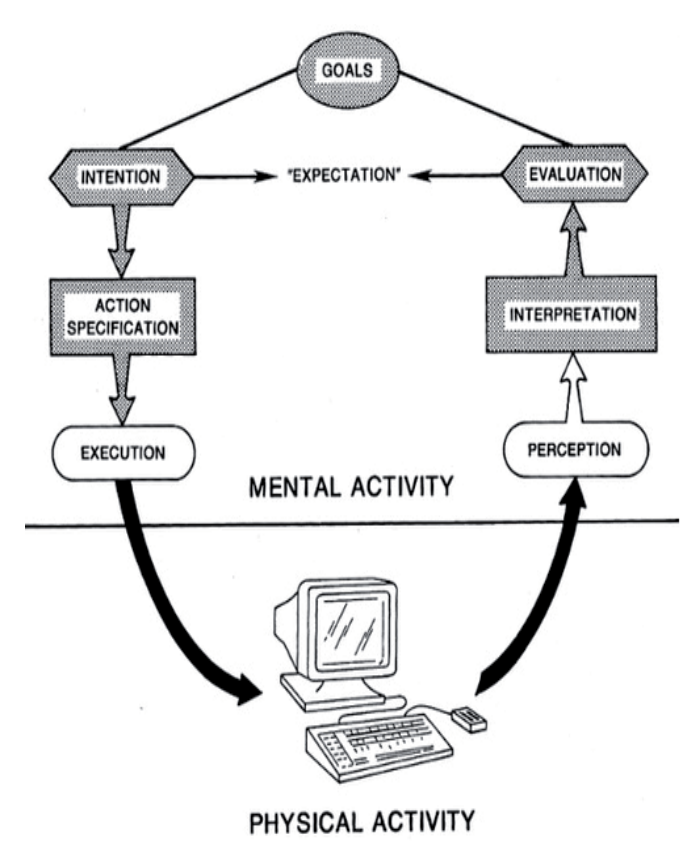

Figure 4. Norman's interaction model (Norman, 1986). 
Abowd and Beale (1991) indicated in their model the following interaction steps. The user communicates with the system via input/output devices (articulation). This is the process of describing a request in the form of a language understandable by a task. The request is executed using a certain core language (performance) and then produce the output to users in a presentation phase. The user may continue with the observation on the results produced or start formulating new goals. With this model, the user's intention is translated into action at the interface, then translated into alterations of system state, which in turn is reflected in the output for further interpretation.

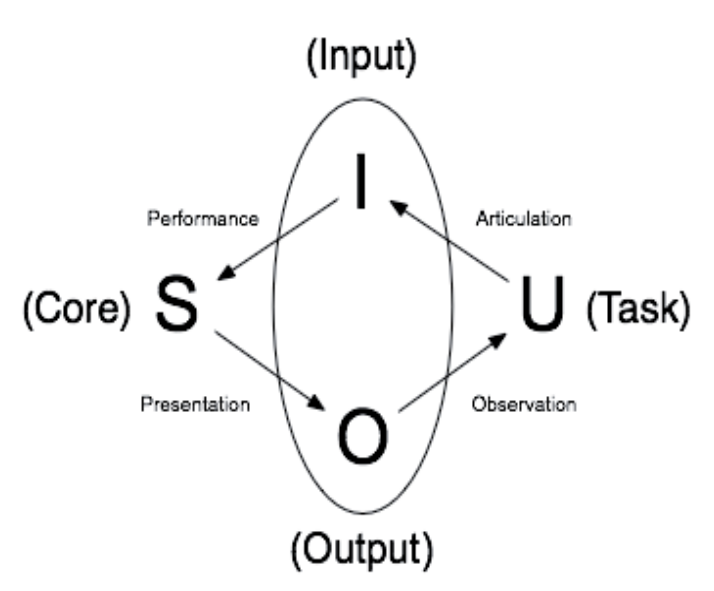

Figure 5. Abowd and Beale’s model of interaction (Abowd \& Beale, 1991).

Applying the interaction models in the context of the dyslexic children, the interaction design should consider impairments such as types of reading errors, fonts, and colours. As for the reading errors, the most frequent types of reading errors need to be incorporated into the ART engine for better recognition accuracy (Husniza, 2010). By having identifying the reading errors, the reading recognition rate could be increased, thus reducing frustration should false alarm occur in the detection while a user is reading (Husniza \& Zulikha, 2010a; Husniza \& Zulikha, 2010b). Should the types of reading errors are not considered for the engine of such an application, the recognition rate could drop significantly as these children normally produce errors that are phonetically very similar such as reading 'abang' as 'adang' (for Bahasa Melayu) or reading 'bed' as 'deb’ (in English). Such phonetically similar errors are a challenge for any speech recognition engine as it is difficult to recognize. If the recognition rate is poor, the ART then could not correctly recognize ' $a p a$ ' from ' $a d a$ '. Hence, the learners might be frustrated and demotivated to read if the ART's rejection rate is high due to poor recognition rate. 
Another concern is that the ART could produce false positive recognition where it accepts incorrect reading as correct, thus disturbing the learning process. It is emphasized that the types of reading errors need to be incorporated and carefully modeled into the ART to boost recognition rate and avoid frustration among these children. The background and foreground (text) colours as well as font types and sizes are also important in the design. These elements should be customizable according to user preferences. Some dyslexic children read better (more correct words than wrong ones) when they are using their favourite colours. Some of them find it easier to read words written on bluecoloured background for example, and some might find other colours ease their reading process. As for font types, it is preferable to use 'Sans Serif' as they found it easier to read (Zulikha et al., 2011).

The errors made imply that there is impairment. The higher the impairment, the more affective IxD qualities that need to be imposed. The relationship between impairment and affection must be taken into account in the design. Embedding such design allows a robust interaction model for dyslexic children, thus ensuring that the ART is capable of giving maximum effect towards the performance of the children's reading. Effective interaction design of the ART's interface shall ease the dyslexic children (User) in reading aloud prompted words (Input) displayed on the screen. The read speech is then recognized (System) and the result is presented back to the user (Output). The children can observe the output i.e. the text produced and later decide what to do next (formulating new goal). In the following section, the translation of the models into IxD is illustrated as a guidance.

Before the models are translated into IxD, it is emphasized that the models should be analysized to ensure its effectiveness and suitability in mapping the impairments and affection in a particular design. In order to produce an effective design for affection, the learners' impairments need to be modeled accordingly. In this case, the model should take into consideration the learners' impairment which reflects their severity that later affects their reading ability. The analysis of the models can be further tested using the previous rule on reading ability as have been discussed i.e.

$$
\text { Reading }=r w_{p 1 \ldots p n}+\text { skill }(a l+r s)
$$

where

$r w_{p 1 \ldots p n}=$ ability to read the words $(r w)$ on the page $(p 1 \ldots n)$

$a l=$ ability to apply linguistics

$a r=$ reasoning skills 
As reading relies on $r w$, it should be better formulated by improvising it to be a function of impairment reduction with the help of affective qualities and IxD dimensions of the ART (perceived as the digital product's form, content and behaviour).

$$
r w_{d 1 \ldots d n}=a q(f+c+b)-i(d s)
$$

where

$d 1 . . . d n=$ display 1 to display $n$

$i=$ impairment

$d s=$ dyslexic severity

$a q=$ affective qualities

$f, c, b=\mathrm{IxD}$ dimension for form, content, behavior

\section{METHODOLOGY}

The methodology used in this work was Goal-Directed Design (GDD), a type of User-Centered Design (UCD) method. A library search about general dyslexic children's characteristics was performed in relation to the related theories as discussed above. The GDD methodology was adapted from Cooper, Reinman, and Cronin (2007) that outlines six steps that include research, modeling, requirements, framework, refinement, and support as depicted in Figure 6. The six steps were carried out in order to obtain significant characteristics of dyslexic children. The characteristics are important data in the development of the model that is specifically-designed to facilitate the affection (emotion) of users when using dyslexic children's reading application.

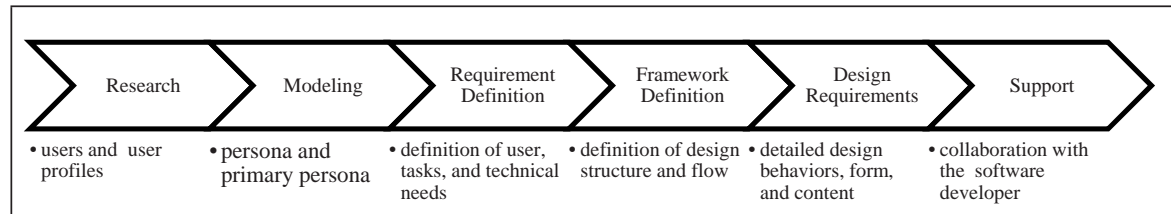

Figure 6. The GDD methodology (Cooper, Reinman, \& Cronin, 2007).

A total of 28 dyslexic children were involved in gathering the information. These children were between 7 and 14 years old who have been randomlyselected to participate in the study. Most of them are from middle-class families whose parents are mostly self-employed. The study was conducted in 
a public primary school that offers special dyslexia classes. An ethnographic interview and observations were performed to gather the data. All 28 children involved were observed and interviewed for user profiling, which is the first step in GDD. To model the user, modeling (second step) was performed where it involved creating a few personas of the profiles generated. The personas included all the significant characteristics of a group of dyslexic children sharing similar characteristics. Among the personas, one person was chosen to be the primary persona, which represent the dominant group of dyslexic children.

In the next step, that is, framework definition, the primary persona was used to elicit the user requirements and suitable features for an affective dyslexic children reading application design. Reference was also made from the literature on studies related to reading application interfaces. Next, the defined design framework was used to obtain the requirements for a more detailed design specification. For example, if the primary persona suggests that they can read better when using different coloured syllables and font types, then the framework should take into consideration the syllable colours and font types. Then, in the design requirement phase, the syllable colours and font types need to be identified specifically so that they could later be incorporated into the actual development of any reading application for dyslexic children (in the support phase). These findings were combined to form the design as discussed in the following section.

\section{TRANSFORMING THEORIES INTO THE MODEL}

In Norman's model, the gap between physical and mental activity is actually the gap between : 1) how the user wants to act and how the system allows or supports the users to take action; and 2) how the computer displays its output as well as how the users interpret the output. To minimize the gap, the tasks in ART are supported by an IxD that addresses the reading patterns, reading interactions and styles of the target users. The form, content, and behaviour dimensions of IxD are designed to reduce the cognitive load of the dyslexic children. Abowd and Beale's model is also taken into account by giving priority to its user component as it represents the learner with dyslexia.

In this context, we observed and interviewed 28 dyslexic children, aged between 7 and 14 years old, in an attempt to finalize the goal decomposition and their reading tasks. The tasks are analyzed to an acceptable level, i.e. when the gap between the physical and mental activities are eliminated. Focusing more directly on aspects that need to support the interaction of dyslexic 
children, each translation step in Abowd and Beale's model was examined so that affective characteristics and specific reading patterns can be mapped onto these translations. Figure 7 illustrates the model with the mapping and translation.

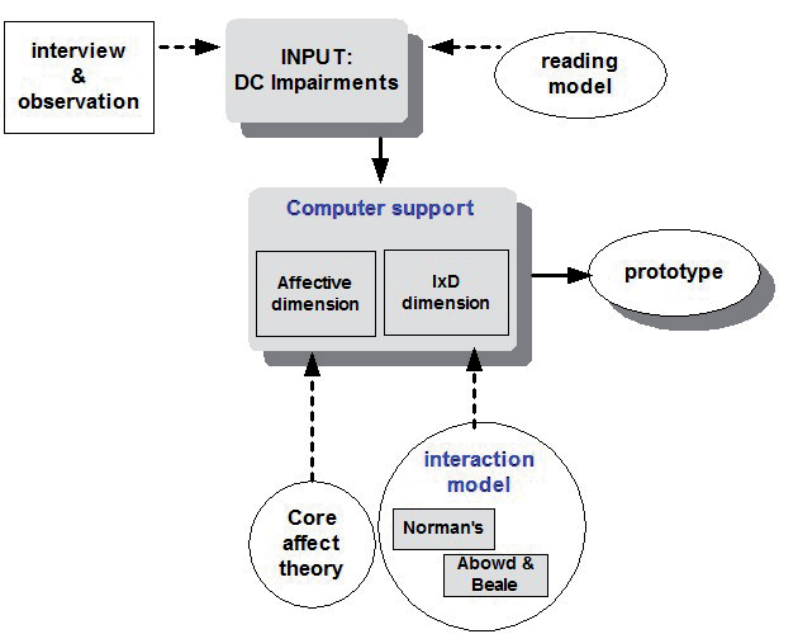

Figure 7. The IxD support model showing the mapping from Norman, Abowd and Beale interaction models (1998).

The IxD elements identified were mapped into the ART as shown in Figure 7. The ART incorporated affective qualities in the behavior dimension of IxD to provide positive reinforcement throughout the spelling and reading tasks. The purpose was to compile both the interaction models discussed above into an ART appropriate for learners with dyslexia. The ART prototype was developed by incorporating all the IxD and affective dimensions (see column 3 and 4 in Figure 8):

- Easy navigation design is proposed to overcome the problem of weak focus on coherence (or easily distracted) with a simple yet attractive interface that includes the affective dimension of curiosity and being relaxed.

- $\quad$ Pen animation that illustrates how to write an alphabet should be included to support the limited cognitive load of dyslexic children. As dyslexic children cannot handle reading a word due to the need for bigger cognitive load to accomplish the task (due to the many theories that trigger the problem such as visual deficits, low-working memory, and temporal or timing difficulties (see Table 1)), pen animation would 
help them remember how an alphabet is shaped. Therefore in order to read a word, the alphabet should be slowly crafted to illustrate the shape of the letter for easier identification. Affective dimension considered are curiosity, awaiting, and eagerness and the IxD dimension includes the level of words, pen size, and the animation speed.

- $\quad$ Different coloured syllables are proposed based on the fact that dyslexic children are affected by words and coloured background (Irlen, 2005). Hence, colours as suggested by Irlen are used for the background colour of text that can be changed easily by the children. The coloured syllables are based on colour theory in IxD.

- $\quad$ Font and syllable handling are based on the observed reading errors made by the children. For example, they tend to substitute, eliminate or replace an alphabet with other alphabet. This suggests that a design of similar looking alphabets such as ' $b$ ' and 'd' do not mirror each other, for example: band d (font type: Wimpy Dyslexia) or 'b' and 'd' (font type: Forte). Users have the control over the type of fonts and choices of similar-looking words that they wish to read. The affective dimensions included in the design are satisfaction and curiosity.

The IxD elements are combined with the affective dimensions as illustrated in Figure 8, which shows the analysis on the children's impairment and the design results obtained after the observation and interview. The figure in actual fact is showing the analysis carried out in deciding the type of computer support, user interface screen objects and content, application behavior, and affective valence to be implemented in the ART.

Combining the affective dimension as described in Figure 8 with the $\mathrm{IxD}$ dimension illustrated in Figure 7, the affective IxD model is achieved. With reference to Figure 7 where input and computer support components are emphasized, the interaction between user and computer is designed so that the ART would incorporate the dyslexic children's affective dimension to achieve the positive learning state as given in the core affect theory. To take this into account, one cannot simply ignore the input, which is the dyslexic children's impairments as they serve as important data for a proper, specific design of an ART to address their difficulties. For a better interaction, all the aforementioned affective attributes that make up the affective dimension need to be supported with a suitable interaction model. In this particular case, Norman's and Abowd and Beale's models were adapted to highlight the interaction between user and computer as has been discussed previously. with reference to Figure 5, the interaction is focused on all the four steps of interactions - reading task (U), input in the form of speech response or read 
speech (I), affective presentation (S) and output (O). Thus, when designing an ART specifically for dyslexic children, each step (U, I, S, O) needs to take into account the affective design elements that have been proposed to ensure better and easier reading for the children.

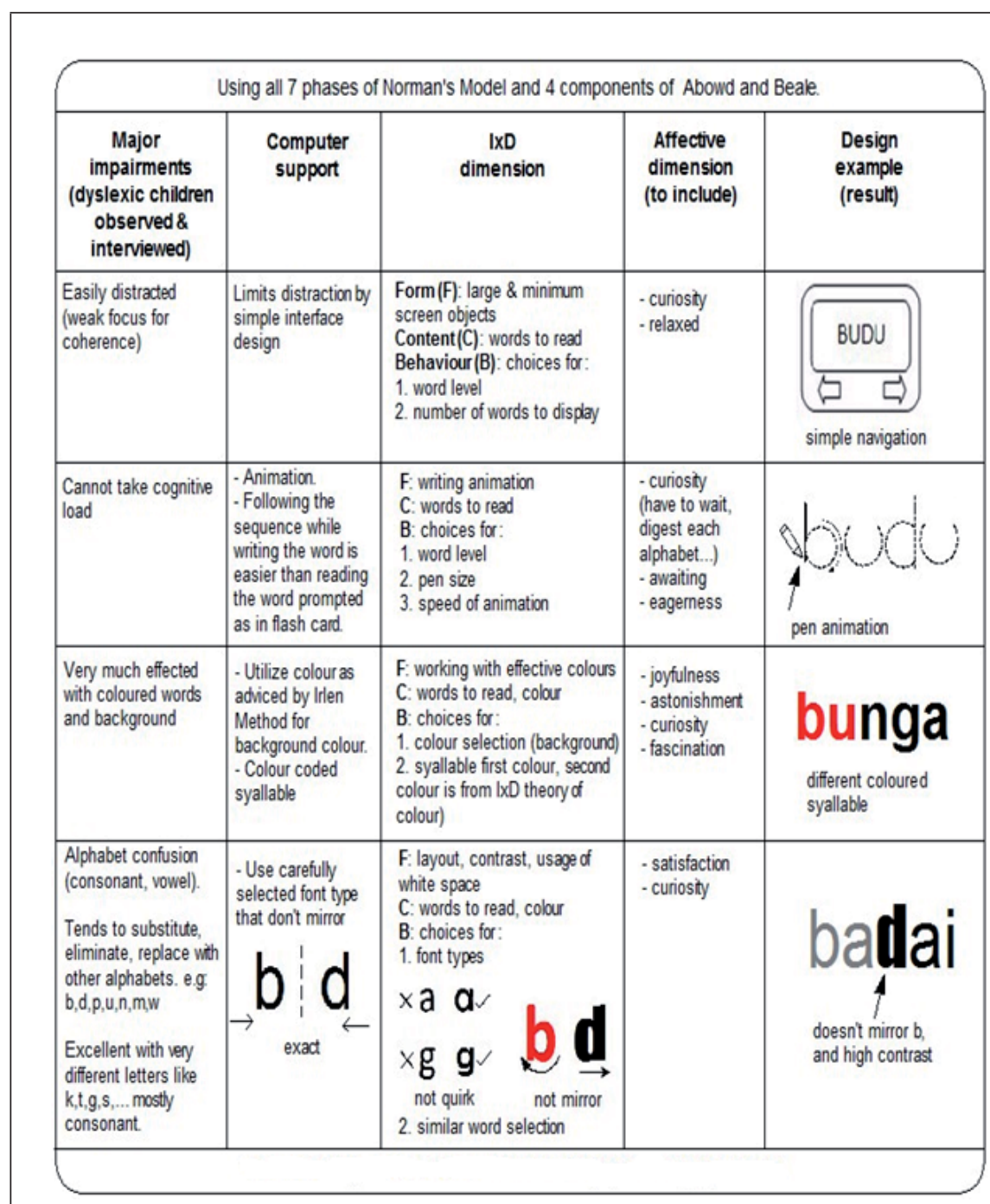

Figure 8 . The analysis on the children's impairment resulting in an affective dimension.

The ART as in Figure 9 is now being tested with dyslexic children of Sekolah Kebangsaan Jalan Dato’ Kumbar, Alor Setar, one of the school in Kedah that includes a special class for a large number of dyslexic children. This model, if 
proven to be predictive for dyslexic children's needs, will lead to a significant contribution in terms of developing guidelines and standards for designing applications targeting at this specific group of users.

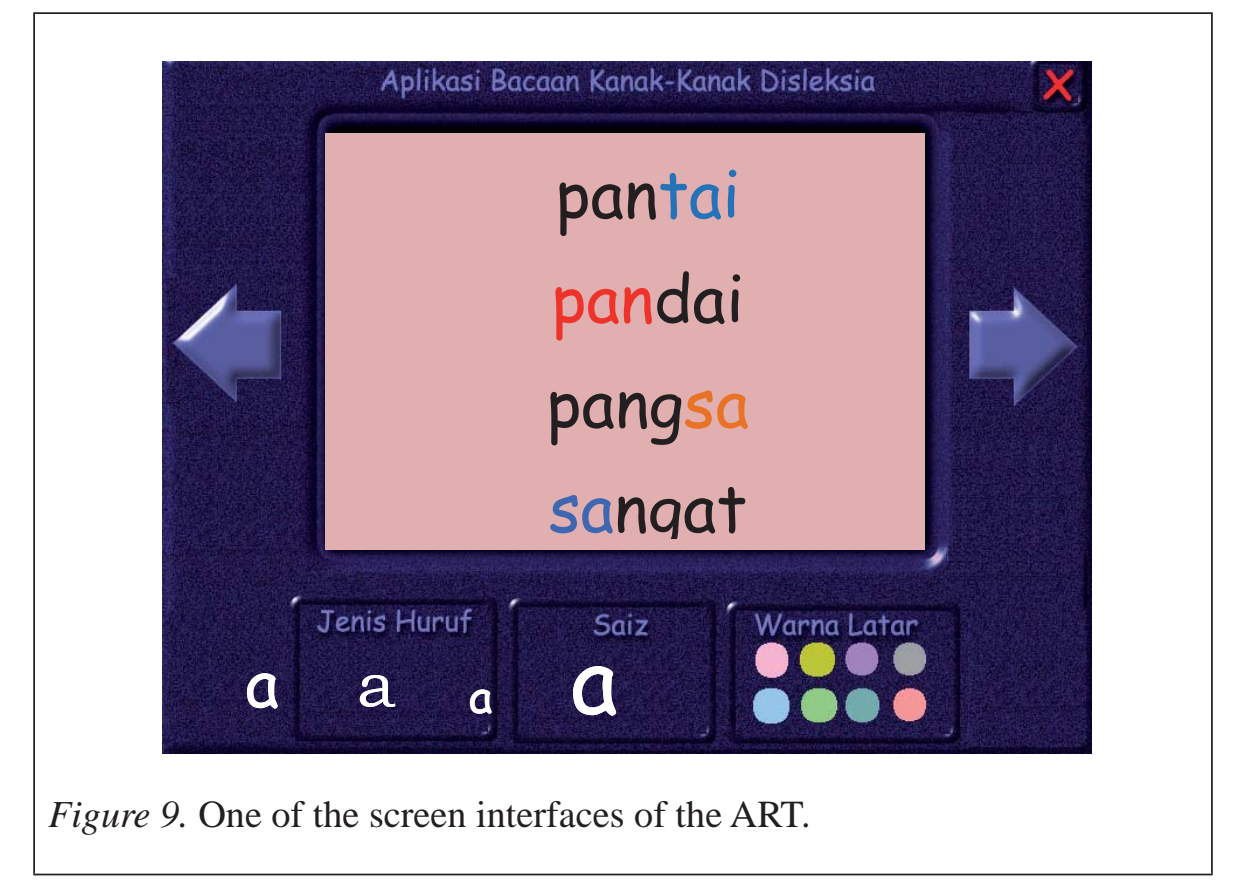

\section{CONCLUSION}

A specific design of an ART is viewed important to cater for the children's needs - the need to have a carefully-designed ART not only focusing on the reading tutor's engine but also the interface of such an application. Hence, the objective of this work is to propose an affective IxD model for dyslexic children's reading application. The interface design plays an important role to develop the children's affection towards reading as well as the learning process. GDD is used as the methodology of this work to extract the affective dimensions of dyslexic chidlren to be incorporated into the design and the model. Special considerations on their need to have suitable and adjustable background colours, different coloured fonts to highlight syllable boundaries in a word, as well as adjustable font types and sizes, for example, would ease the learning process. Hence, the proposed model that combines the two interaction models by Norman and Abowd (1986) as well as Beale (1991), caters to the need to: 1) present the content or objective of an ART that meets the learners' goal, intention, and expectation; and 2) ensure that the learning 
process is effectively delivered when the learners use the ART. Therefore, affective qualities such as satisfaction, joyfulness, relaxation, and fascination, that satisfy the IxD dimension for dyslexic children need to be incorporated into the design of an ART. The model also enhances the reading rule proposed by Wright, i.e. the ability to read the words on the page (display) is defined as a function of impairment reduction with the help of affective qualities and IxD dimensions of the ART specifically as the digital product's form, content and behavior $\left(r w_{d 1 \ldots d n}=i(d s)-a q(f+c+b)\right.$. This proposed affective IxD model needs further study and an evaluation process is being carried out. It is yet to be claimed as a pedagogically sound design that results in a more effective reading tutor design for the special education context.

\section{REFERENCES}

Abowd, G. D., \& Beale, R. (1991). User systems and interfaces: A unifying framework for interaction. In D. Diaper \& N. Hammond (Eds.), HCI '91: People and computers VI. (pp. 239-252). Cambridge: Cambridge University Press.

Cooper, A., Reiman, R. \& Cronin, D. (2007). About face: The essentials of interaction design (3rd ed.). Indianapolis: John Wiley.

Desmet, P. M. A. (2007). Product emotion. In H. N. J. Schifferstein \& P. Hekkert (Eds.), Product experience. New York: Elsevier Science Publishers.

Fakhrul A. A., Husniza, H., \& Zulikha, J. (2010). Affective engineering: What is it actually? Proceedings of 5th Knowledge Management International Conference (KMICE). Kuala Terengganu, Malaysia.

Fuwcett, A., \& Nicolson, R. (1992). Dyslexia: The role of the cerebellum. Electronic Journal of Research in Educational Psychology, 2(2), 35-50.

Husniza, H. (2010). Automatic speech recognition model for dyslexic children reading in Bahasa Melayu (Unpublished doctoral dissertation).Sintok: Universiti Utara Malaysia.

Husniza, H., \& Zulikha J. (2010a) Improving ASR performance using contextdependent phoneme models. Journal of Systems and Information Technology (JSIT), 12(1), 56-69. 
Husniza, H. \& Zulikha, J. (2010b). Minimizing word error rate in a dyslexic reading-oriented ASR engine using phoneme refinement and alternative pronunciation. Proceedings of International Conference on Education and New Learning Technologies EDULEARN'10, Barcelona. Spain.

Husniza, H., \& Zulikha, J. (2009). Dyslexic children's reading pattern as input for ASR: Data, analysis, and pronunciation model. Journal of Information and Communication Technology (JICT), 8, 1-13.

Irlen, H. (2005). Reading by the colors: Overcoming dyslexia and other reading disabilities through the Irlen method. New York: Penguin Group.

Lundberg, I., \& Olofsson, A. (1993). Can computer speech support reading comprehension? Computers in Human Behavior, 9, 283-293.

Lundberg, I. (1995). The computer as a tool of remediation in the education of students with reading disabilities: A theory-based approach. Learning Disability Quarterly, 18(2), 88-99.

Norman, D. (1986). Cognitive engineering. In Donald Norman \& Stephen Draper (Eds.), User centered design: New perspectives on humancomputer interaction (pp. 31-62). Hillsdale, N. J. : Erlbaum Associates.

Norman, D. A. (1998). The psychology of everyday things. New York: Basic Books.

Olofsson, A. (1992). Synthetic speech and computer aided reading for reading disabled children. Reading and Writing: An Interdisciplinary Journal, 4, 165-178.

Olson, R. K., \& Wise, B. W. (1992). Reading on the computer with orthographic and speech feedback: An overview of the Colorado remediation project. Reading and Writing: An Interdisciplinary Journal, 4, 107-144.

Paulesu, F. et al. (2001). Dyslexia: Cultural divesity and biological unity. Science, 291, 2165-2167.

Russell, J. A. (2003). Core affect and the psychological construction of emotion. Psychological Review, 110(1), 145-172.

Shaywitz, S. E. (1996, November). Dyslexia. Scientific American, 98-104. 
Syayuitz, S. E., \& Shayuitz, B. A. (1999). Dyslexia. Specific Reading Disability Journal.

Snowling, M. J. (2000). Dyslexia (2nd ed.). UK: Blackwell Publishers.

Stein, J., \& Walsh, V. (1997). To see but not to read. The magnocellular theory of dyslexia. Trend in Neurosciences.

Te'eni, D., Carey, J., \& Zhang, P. (2007). Human computer interaction: Developing effective organizational information systems. USA: John Wiley \& Sons.

Wolf, M. (1999). What time may tell: Towards a new conceptualization of developmental dyslexia. Annals of Dyslexia, 49, 3-28.

Wright, C. (2010). Understanding words: A brief history. Retrieved from http://www.understandingwords.com.au/public/dyslexia_information. php.

Zulikha, J. Husniza, H., \& Fakhrul, A. A. (2011). An IxD support model with affective characteristics for dyslexic children's reading application. Proceedings of the 3rd International Conference on Computing and Informatics, ICOCI 2011,8-9 June, 2011 Bandung, Indonesia. 